\title{
Phase I clinical trial of a peptide vaccine combined with tegafur-uracil plus leucovorin for treatment of advanced or recurrent colorectal cancer
}

\author{
NORIMASA MATSUSHITA ${ }^{1}$, ATSUSHI ARUGA ${ }^{1}$, YUJI INOUE ${ }^{1}$, YOSHIHITO KOTERA ${ }^{1}$, \\ KAZUYOSHI TAKEDA ${ }^{2}$ and MASAKAZU YAMAMOTO ${ }^{1}$ \\ ${ }^{1}$ Department of Surgery, Institute of Gastroenterology, Tokyo Women's Medical University; \\ ${ }^{2}$ Department of Immunology, Juntendo University School of Medicine, Tokyo, Japan
}

Received October 24, 2012; Accepted December 7, 2012

DOI: 10.3892/or.2013.2231

\begin{abstract}
Recently, analysis of tumor antigens using microarrays has revealed upregulation of cancer-testis antigens RNF43 and TOMM34 and vascular endothelial growth factor receptors VEGFR1 and VEGFR2 in colorectal cancer. A phase I clinical trial of peptide vaccine therapy together with oral anticancer drugs was conducted to treat advanced colorectal cancer using synthesized peptides of these tumor antigens in order to confirm the safety, immunogenicity and activity of this treatment. The subjects were patients with a human leukocyte antigen (HLA) type of A2402 who had inoperable colorectal cancer but had failed to respond to or were unable to undergo standard chemotherapy. Four peptides (RNF43, TOMM34, VEGFR1 and VEGFR2) were emulsified with incomplete Freund's adjuvant (Montanide), and the resulting solution was administered subcutaneously once a week. Patients received the oral anticancer drug tegafur-uracil plus leucovorin for four weeks continuously as part of one course followed by one week of rest. The primary endpoint of the trial was observation of adverse events as determined by the NCI-CTCAE criteria, and the secondary endpoints were the size of the tumor and the number of cytotoxic $\mathrm{T}$ lymphocytes (CTLs) in the peripheral blood after treatment. Vaccine therapy was administered 148 times to 10 patients from July 2008 to December 2009. The adverse events were grade 1 redness and induration, a grade 2 skin ulcer at the vaccination site and grade 1 pyrexia. All patients tolerated treatment. Tumor imaging revealed that after 1 course of treatment 1 patient had partial response (PR), 7 had stable disease (SD) and 2 had progressive disease. A CTL assay of 10 patients revealed
\end{abstract}

Correspondence to: Dr Atsushi Aruga, Department of Surgery, Institute of Gastroenterology, Tokyo Women's Medical University, 8-1 Kawada-cho, Shinjuku-ku, Tokyo 162-8666, Japan

E-mail: aruga@abmes.twmu.ac.jp

Key words: peptide vaccine, colorectal cancer, chemotherapy, clinical trial, immunotherapy an increase in peptide-specific CTLs in patients with PR and $\mathrm{SD}$, and the clinical responses of those patients were observed. Kaplan-Meier analysis indicated that patients who had a strong CTL reaction had a tendency to have longer progression-free survival and overall survival.

\section{Introduction}

Peptide vaccine therapies using peptides synthesized on the basis of amino acid sequences of tumor antigens are considered safe and efficacious in treating cancers such as hematologic malignancies, prostatic cancer, pancreatic cancer, and renal cancer, and such peptide vaccine therapies may represent a new mode of treatment. In recent years, translocase of the outer mitochondrial membrane 34 (TOMM34) and ring finger protein 43 (RNF43) have been identified as cancer-testis antigens that are expressed in malignant colon cancer, and vascular endothelial growth factor receptors VEGFR1 and VEGFR2 have also been identified in malignant colon cancer through use of microarrays. In order to evaluate the safety of cancer vaccine therapy using peptides based on the amino acid sequences of these tumor antigens, a phase I clinical trial of peptide vaccine therapy together with the oral anticancer drug tegafur-uracil (UFT) plus leucovorin $(\mathrm{LV})$ was conducted to treat inoperable advanced or recurrent colorectal cancer. The registration number was UMIN000004452.

\section{Materials and methods}

Purpose. The aim of this study was to evaluate the safety of peptide vaccines in treating colorectal cancer.

Subjects. The subjects were patients with a human leukocyte antigen (HLA) type of HLA-A2402 who had inoperable advanced or recurrent colorectal cancer. All patients meeting eligibility criteria were included and those meeting exclusion criteria were excluded as subjects. Eligible patients had colorectal cancer according to an imaging study and histology and a performance status (ECOG scale) between 0 and 2. Eligible patients were between 20 and 80 years of 
age. Patients' tumors were not amenable to surgical treatment by curative resection and did not respond to guideline-based chemotherapy; eligible patients had a predicted prognosis of at least 3 months. Eligible patients did not have severely impaired organ function (bone marrow, liver and kidneys). Eligible patients had blood test results that met criteria (WBC $>2000 / \mathrm{mm}^{3}$ and $<10000 / \mathrm{mm}^{3}$; hemoglobin $>8.0 \mathrm{~g}$ / dl; platelets $>10 \times 10^{4} / \mathrm{mm}^{3}$; creatinine within normal limits; AST and ALT <100 U/1). Patients' tumors were not treated at least 4 weeks prior to vaccination. Patient consent for trial participation was confirmed via a written consent form approved by the Institutional Review Board of Tokyo Women's Medical University. Female patients who were pregnant or breast feeding and patients with serious underlying conditions (serious active infectious disease, circulatory disorder, respiratory disorder, renal disorder, immune function disorder, blood coagulation disorder) or severe allergies were excluded from this trial. Patients deemed ineligible by the clinical investigator were also excluded.

Protocol. Prior to start of the trial, the treatment was approved by an Institutional Review Board of Tokyo Women's Medical University. All procedures followed were in accordance with the Helsinki Declaration. Four peptides (RNF43, TOMM34, VEGFR1 and VEGFR2) were emulsified with Montanide and the resulting solution was administered subcutaneously near the inguinal lymph node once a week. Patients received the oral anticancer drug UFT+LV three times a day every $8 \mathrm{~h}$. UFT (300 mg/m²/day) and LV (75 mg/day) were administered for 4 weeks continuously as part of one course followed by 1 week of rest. Prior to the start of the trial and during the 1 week rest for every course, patients received imaging study, blood test and immune monitoring through blood test. During the 4 weeks prior to receiving the vaccine and during the first 2 courses of vaccination (10 weeks), patients did not receive any other anticancer treatment.

\section{Peptides and drugs}

Peptides. The peptides used in this trial were RNF43, TOMM34, VEGFR1 and VEGFR2. The peptides were identified as cancer-testis antigens and vascular endothelial growth factor receptors. Cancer-testis antigens are expressed only on the cell surface of the testicles in normal tissue. Since the cells of the testicles do not express the HLA molecule on their surface, the body's immune system does not attack these cells. The peptides were sterilely manufactured in accordance with good manufacturing practice (GMP) standards, and preclinical trials had previously confirmed that the peptides did not produce acute toxicity.

TOMM34. Translocase exists in the inner and outer membrane of mitochondria, and this enzyme plays an important role in maintaining mitochondrial transmembrane function. TOMM34 is a $34-\mathrm{kDa}$ translocase present on the outer membrane of mitochondria. This enzyme transports precursor proteins and has been identified as a new cancer antigen (1). Over $80 \%$ of colon cancers express the antigen on the cell surface. Although the cells of the testicles and ovaries express the antigen, other normal tissues do not. A colon cancer cell line with TOMM34 suppressed by siRNA exhibited inhibition of cell growth, suggesting that TOMM34 may be involved in tumor growth (1). Moreover, cytotoxic T lymphocytes (CTLs) recognizing the TOMM34 peptide demonstrated a high cytotoxic effect on a colon cancer cell line in vitro, suggesting that TOMM34 may be a target cancer antigen for use in therapy.

RNF43. RNF43 was identified as a gene overexpressed in colon cancer by profiling using cDNA microarrays (2). RNF43 exists as a protein in the nucleus and cytoplasm and is also a secretory protein (3). Over $85 \%$ of colon cancers express RNF43, and fetal kidneys and lungs weekly express RNF43 although normal tissues do not express the protein (3). A cell line overexpressing RNF43 was shown to have increased cell proliferation, and suppression of RNF43 by siRNA inhibited cell growth, suggesting that RNF43 is involved in tumor growth (3).

VEGFR1 and VEGFR2. VEGFR is a tyrosine kinase receptor and is classified as VEGFR1, VEGFR2 and VEGFR3 (4). The binding of VEGF to VEGFR stimulates angiogenesis and tumor growth. Anticancer drugs targeting VEGFR have already been proven clinically efficacious, and vaccination against VEGFR results in antitumor action in clinical settings $(5,6)$. Moreover, CTLs recognizing VEGFR are present in the peripheral blood of cancer patients, suggesting the potential for peptide vaccine therapy targeting VEGFR (7).

Montanide ISA-51VG. Montanide is a sterile vaccine adjuvant manufactured by SEPPIC Co. (Puteaux, France) in accordance with GMP standards and is also known as incomplete Freund's adjuvant. Montanide is currently used as an adjuvant in vaccine therapy worldwide, and serious adverse events due to Montanide have yet to be reported. Montanide has been used as an adjuvant in clinical trials by many facilities in Japan and was thus used as an adjuvant for the peptides in the present trial. Since no adverse events due to Montanide have been reported, it is deemed safe for administration.

$U F T+L V$. UFT and LV are oral anticancer drugs marketed in Japan and approved for treatment of colorectal cancer. $\mathrm{UFT}+\mathrm{LV}$ has the same response rate as fluorouracil (5-FU)+LV. UFT+LV inhibits DNA synthesis and RNA function in cancer cells and has anticancer action $(8,9)$.

Evaluation of safety. Adverse events resulting from the peptide vaccine were evaluated using the National Cancer Institute's Common Terminology Criteria for Adverse Events (NCI-CTCAE) v3.0.

Evaluation of antitumor action and endpoint. The present clinical trial evaluated safety, thus antitumor action was not evaluated. However, changes in tumor markers and tumor size were recorded during the trial. The primary endpoint was evaluation of the safety of peptide vaccines, and secondary endpoints were tumor size as determined by an imaging study in accordance with the RECIST guideline (10), the number of CTLs according to an ELISpot assay, and phenotypes of $\mathrm{T}$ cells in peripheral blood during treatment. 


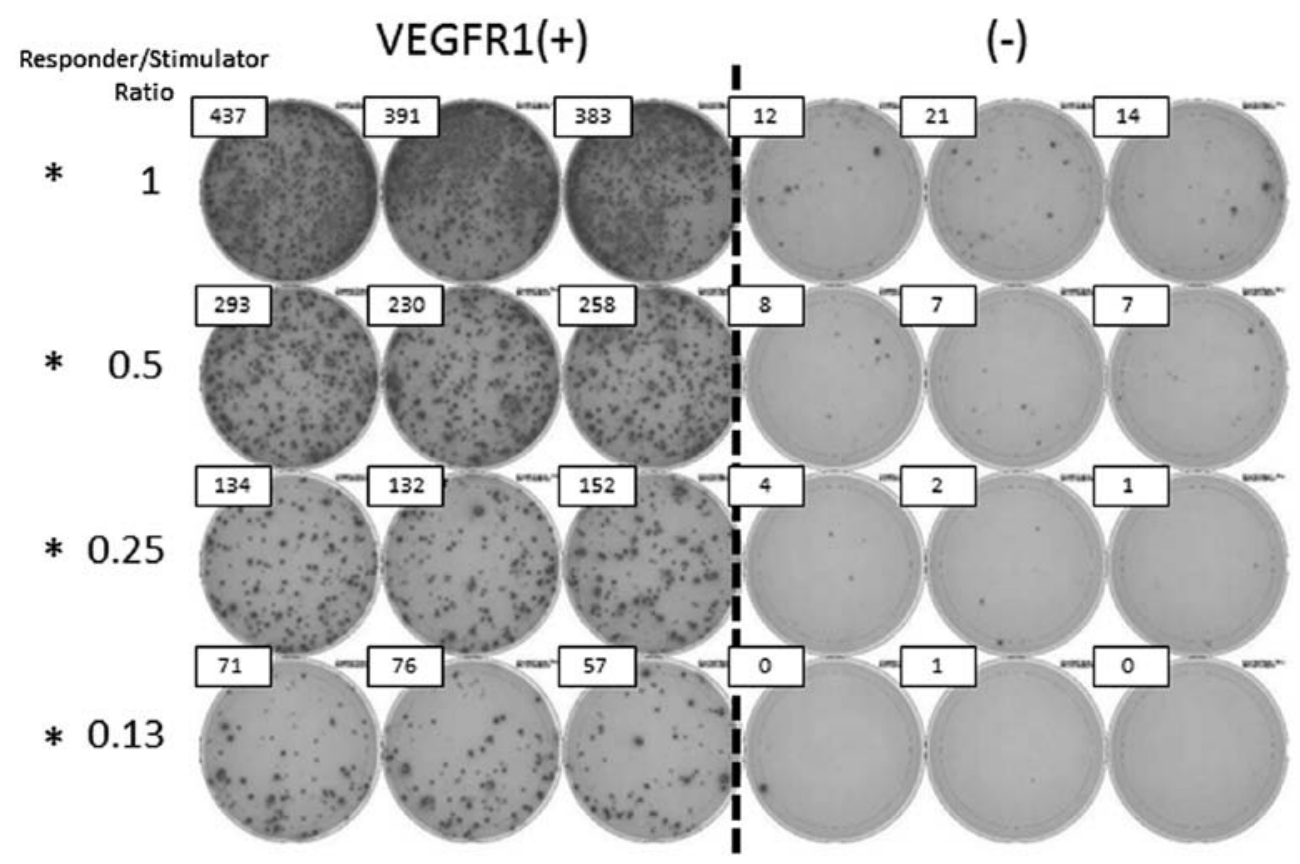

Figure 1. IFN- $\gamma$ ELISpot assay (patient no. 4, following 1 course of treatment). IFN- $\gamma$ ELISpot assay was performed with blood samples from patient no. 4 after 1 course of treatment. The numbers indicate the number of spots. Lymphocytes from the blood samples were stimulated with VEGFR1 peptide for the assay. To provide a negative control, lymphocytes were not stimulated with peptide. ${ }^{*} \mathrm{P}<0.05$.

Enzyme-linked immunospot (ELISpot) assay. Specific CTL response was estimated by ELISpot assay following in vitro sensitization. Frozen peripheral blood mononuclear cells (PBMCs) derived from the same patient were thawed at the same time, and the viability was confirmed to be $>90 \%$. PBMCs $\left(5 \times 10^{5} / \mathrm{ml}\right)$ were cultured with $10 \mu \mathrm{g} / \mathrm{ml}$ of respective peptide and $100 \mathrm{IU} / \mathrm{ml}$ of interleukin-2 (Novartis, Emeryville, CA, USA) at $37^{\circ} \mathrm{C}$ for 2 weeks. The peptide was added into the culture on Day 0 and on Day 7. Following CD4+ cell depletion using the Dynal CD4 Positive Isolation kit (Invitrogen, Carlsbad, CA, USA), interferon- $\gamma$ (IFN- $\gamma$ ) ELISpot assay was performed using the Human IFN- $\gamma$ ELISpot Plus kit (Mabtech AB, Nacka Strand, Sweden) according to the manufacturer's instructions. Briefly, HLA-A2402-positive B-lymphoblast TISI cells (IHWG Cell and Gene Bank, Seattle, WA, USA) were incubated with $20 \mu \mathrm{g} / \mathrm{ml}$ of vaccinated peptides overnight, then the residual peptide in the media was washed out to prepare peptide-pulsed TISI cells as the stimulator cells. Prepared CD4- cells were cultured with peptide-pulsed TISI cells $\left(2 \times 10^{4}\right.$ cells/well $)$ at $1 / 1,1 / 2$, $1 / 4$ and $1 / 8$ mixture ratio of responder cells and stimulator cells (R/S ratio) on a 96-well plate (Millipore, Bedford, MA, USA) at $37^{\circ} \mathrm{C}$ overnight. Non-peptide-pulsed TISI cells were used as negative control stimulator cells. To confirm IFN- $\gamma$ productivity, responder cells were stimulated with phorbol 12-myristate 13-acetate (PMA) $(66 \mathrm{ng} / \mathrm{ml})$ and ionomycin (3 $\mu \mathrm{g} / \mathrm{ml})$ overnight, and then applied to the IFN- $\gamma$ ELISpot assay $\left(2.5 \times 10^{3}\right.$ cells/well) without stimulator cells. All ELISpot assays were performed using triplicate wells. The plates were analyzed by an automated ELISpot reader, ImmunoSpot S4 (Cellular Technology Ltd., Shaker Heights, OH, USA) and ImmunoSpot Professional Software version 5.0 (Cellular Technology Ltd.). The number of peptide-specific spots was calculated by subtracting the spot number in the control well from the spot number in the well with the peptide-pulsed TISI cells. Sensitivity of our ELISpot assay was estimated to be approximately equal to the average level by the ELISpot panel of the Cancer Immunotherapy Consortium [CIC (http://www. cancerresearch.org/consortium/assay-panels/)].

Statistical analysis. Overall survival (OS) and progression-free survival (PFS) were analyzed by the Kaplan-Meier method, and the statistical differences were analyzed by the log-rank method. The Student's t-test was performed to compare results between the two groups. Data were considered to be statistically significant when a P-value of $<0.05$ was achieved.

\section{Results}

The subjects consisted of 8 males and 2 females, ages 40 to 70 years (average age, 58.4 years). The lesions evaluated were from 7 metastatic liver tumors, 3 metastatic lung tumors, 1 metastatic lesion to pleura, 2 lesions indicating local recurrence in the pelvis and 2 lesions indicating peritoneal dissemination (patients may have had more than one type of lesion) (Table I). The 10 patients were administered the vaccine 8 to 28 times (148 times in total) from July 2008 to December 2009. The dosage was increased to $0.5 \mathrm{mg}$ for 3 patients, $1 \mathrm{mg}$ for 3 and $3 \mathrm{mg}$ for 4 . All doses were safely administered. During the therapy, 1 patient suffered from hematuria and urinary retention. These events were observed in a patient suffering from local recurrence of sigmoid colon cancer, thus these events were attributed to the tumor itself. The other adverse event was grade 1 pyrexia, which was successfully treated on an outpatient basis. All of the patients had a skin reaction at the vaccination site. The skin reactions were grade 1 redness, induration, and bullosis in 8 patients and grade 2 ulceration of the vaccination site in 2 patients. All skin reactions were adequately treated 


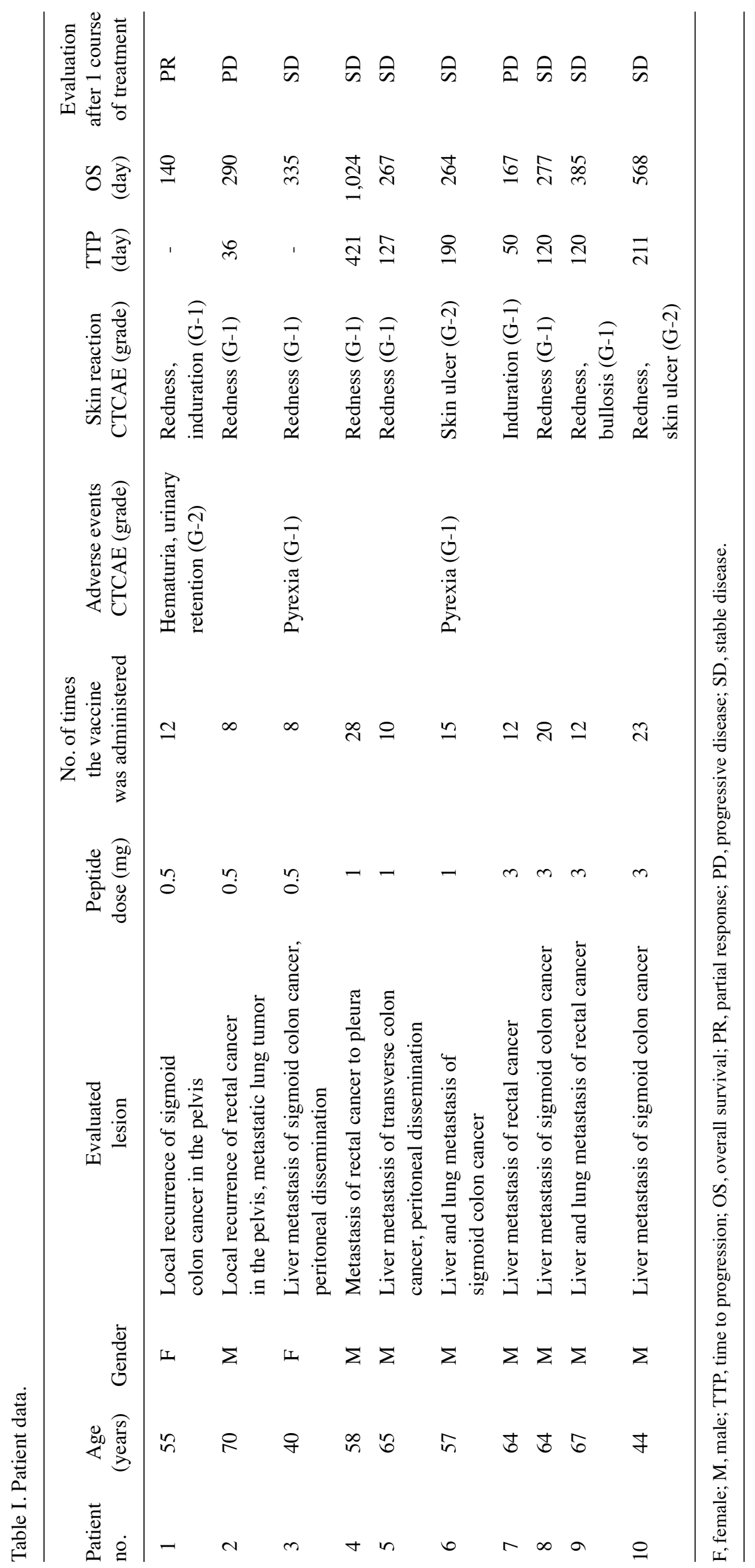


Table II. CTL assessment (IFN- $\gamma$ ELISpot assay).

\section{CTL response}

\begin{tabular}{|c|c|c|c|c|c|c|c|c|}
\hline $\begin{array}{l}\text { Peptide } \\
\text { dose }\end{array}$ & $\begin{array}{l}\text { Patient } \\
\text { no. }\end{array}$ & Course & RNF43 & TOMM34 & VEGFR1 & VEGFR2 & $\begin{array}{l}\text { Positive } \\
\text { control }\end{array}$ & $\begin{array}{c}\text { Evaluation after } \\
1 \text { course of treatment }\end{array}$ \\
\hline \multirow[t]{10}{*}{$0.5 \mathrm{mg}$} & \multirow[t]{4}{*}{1} & Pre & + & - & - & +++ & +++ & PR \\
\hline & & Post1 & + & + & +++ & +++ & +++ & \\
\hline & & Post 2 & + & - & +++ & ++ & +++ & \\
\hline & & Post3 & - & ++ & +++ & + & +++ & \\
\hline & \multirow[t]{3}{*}{2} & Pre & - & - & + & - & + & PD \\
\hline & & Post 1 & - & - & + & + & + & \\
\hline & & Post2 & - & - & + & - & + & \\
\hline & \multirow[t]{3}{*}{3} & Pre & - & + & - & + & + & SD \\
\hline & & Post1 & + & + & + & + & + & \\
\hline & & Post2 & - & - & +++ & - & ++ & \\
\hline \multirow[t]{13}{*}{$1 \mathrm{mg}$} & \multirow[t]{7}{*}{4} & Pre & + & + & - & + & +++ & SD \\
\hline & & Post 1 & - & - & +++ & + & +++ & \\
\hline & & Post 2 & - & - & +++ & + & +++ & \\
\hline & & Post2 (resume) & - & - & ++ & +++ & +++ & \\
\hline & & Post3 & + & - & - & + & +++ & \\
\hline & & Post5 & + & - & - & + & +++ & \\
\hline & & Post6 & - & - & + & + & +++ & \\
\hline & \multirow[t]{3}{*}{5} & Pre & + & + & + & - & + & SD \\
\hline & & Post1 & - & - & +++ & - & +++ & \\
\hline & & Post 2 & - & - & + & - & ++ & \\
\hline & \multirow[t]{3}{*}{6} & Pre & - & - & - & - & +++ & SD \\
\hline & & Post1 & - & - & ++ & + & +++ & \\
\hline & & Post 2 & - & - & ++ & + & +++ & \\
\hline \multirow[t]{20}{*}{$3 \mathrm{mg}$} & \multirow[t]{4}{*}{7} & Pre & - & - & + & - & +++ & PD \\
\hline & & Post1 & - & - & ++ & - & +++ & \\
\hline & & Post2 & - & - & ++ & - & +++ & \\
\hline & & Post3 & - & - & +++ & + & +++ & \\
\hline & \multirow[t]{6}{*}{8} & Pre & + & - & + & + & +++ & SD \\
\hline & & Post1 & + & - & + & + & +++ & \\
\hline & & Post 2 & - & - & ++ & - & +++ & \\
\hline & & Post3 & + & - & +++ & - & +++ & \\
\hline & & Post4 & - & - & ++ & ++ & +++ & \\
\hline & & Post5 & + & - & +++ & +++ & +++ & \\
\hline & \multirow[t]{4}{*}{9} & Pre & - & + & - & - & +++ & SD \\
\hline & & Post1 & - & - & - & - & +++ & \\
\hline & & Post2 & + & - & +++ & + & +++ & \\
\hline & & Post3 & - & - & ++ & + & +++ & \\
\hline & \multirow[t]{6}{*}{10} & Pre & ++ & + & ++ & ++ & +++ & SD \\
\hline & & Post1 & ++ & - & ++ & + & +++ & \\
\hline & & Post2 & ++ & - & +++ & ++ & +++ & \\
\hline & & Post3 & + & + & - & +++ & +++ & \\
\hline & & Post4 & ++ & - & + & +++ & +++ & \\
\hline & & Post5 & + & - & ++ & +++ & +++ & \\
\hline
\end{tabular}

Summary of the CTL assay (IFN- $\gamma$ ELISpot assay) results for all patients. +++ indicates a strong CTL reaction to the peptides. PR, partial response; $\mathrm{PD}$, progressive disease; $\mathrm{SD}$, stable disease.

and managed on an outpatient basis. In all patients, CTLs in the peripheral blood were evaluated by IFN- $\gamma$ ELISpot assay. CTLs tended to be induced by VEGFR1 in patients with a partial response (PR) and stable disease (SD). In the patient with PR, 
A

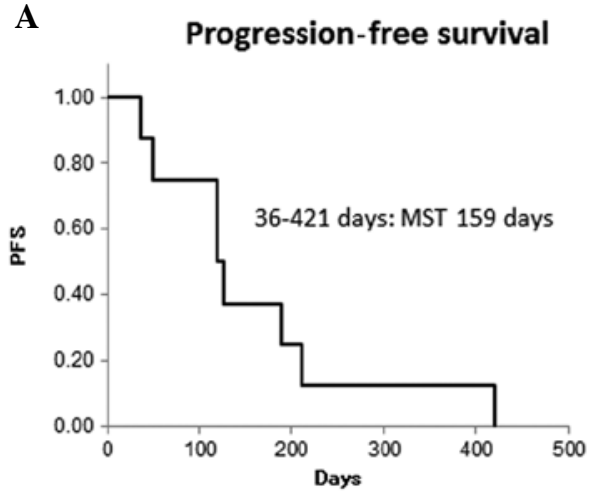

C

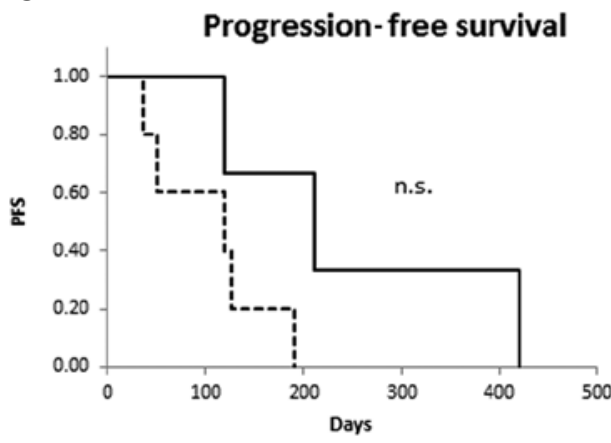

B

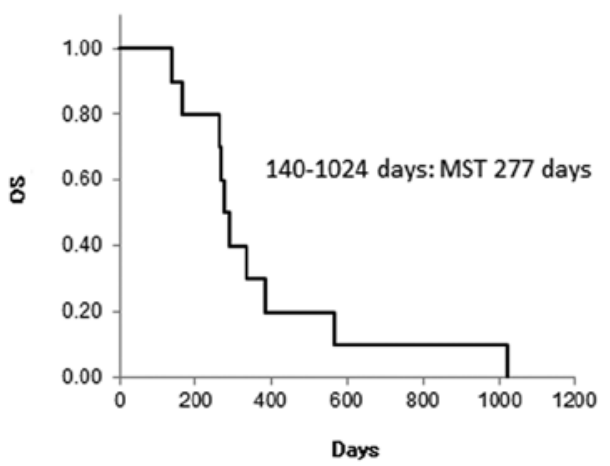

D

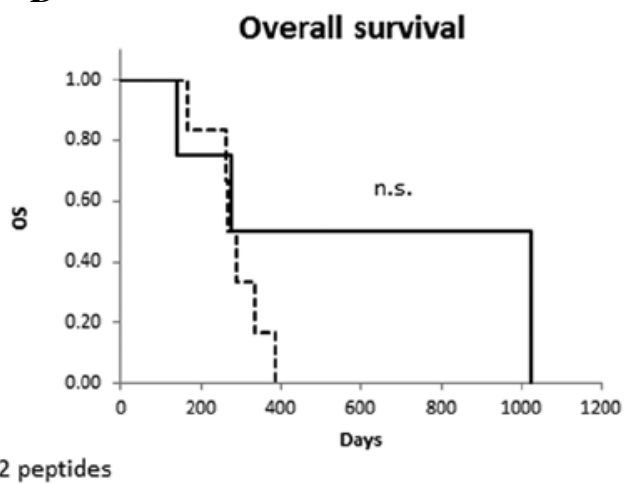

Figure 2. Kaplan-Meier curves indicating (A) progression-free survival (PFS) and (B) overall survival (OS) for all patients. PFS ranged from 36 to 421 days (MST, 159 days) and OS ranged from 140 to 1,024 days (MST, 277 days). Kaplan-Meier curves for (C) PFS and (D) OS in two groups classified by their CTL reaction. A solid line indicates patients with a strong CTL response to more than 2 peptides and a dotted line indicates patients with a strong CTL response to less than 1 peptide. n.s., not significant. MST, median survival time.

\section{MRI}

A

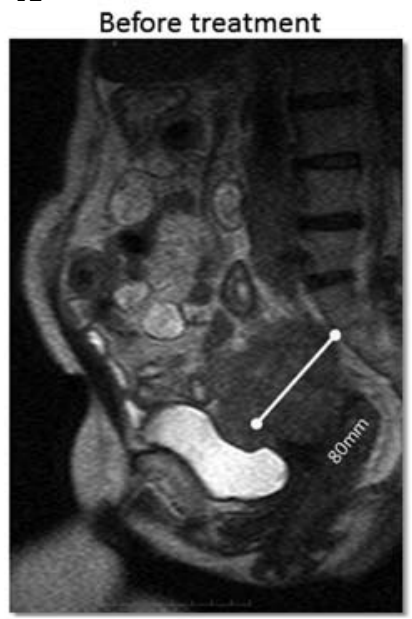

\section{B}

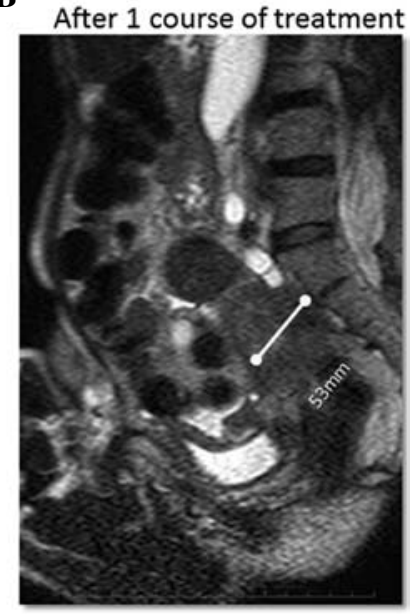

Figure 3. Patient no. 1 (local recurrence of sigmoid colon cancer in the pelvis). (A) This MRI scan shows local recurrence of sigmoid colon cancer in the pelvis before treatment. The tumor was $80 \mathrm{~mm}$ in size. (B) After 1 course of treatment, the tumor decreased in size to $53 \mathrm{~mm}$.

CTLs recognizing RNF43, TOMM34 and VEGFR2 were also induced. In the patient with progressive disease (PD), a limited CTL response was observed (Fig. 1) (Table II). PFS ranged from 36 to 421 days [median survival time (MST), 159 days] and OS ranged from 140 to 1,024 days (MST, 277 days). Kaplan-Meier analysis indicated that patients who had a strong CTL reaction $(+++)$ to more than 2 peptides had a longer PFS and OS, but the difference was not statistically significance (Fig. 2). Evaluation of tumor size via an imaging study after 1 course of treatment revealed that 1 patient had a PR, 7 had a SD and 2 had a PD. In the patient with PR, a tumor in the pelvis decreased more than $30 \%$ in size (Fig. 3). One patient had an extended SD (patient no. 4). The patient was diagnosed with pleural metastasis of rectal cancer in August 2007 (Fig. 4A). After the diagnosis, the patient underwent chemotherapy [FOLFOX+bevacizumab, FOLFIRI+bevacizumab and S-1 (a combination of tegafur, gimeracil, and oteracil potassium) + oxaliplatin] for $\sim 10$ months. Based on an imaging study, the patient was deemed to have PD in July 2008 (Fig. 4B). After enrollment in the clinical trial, the patient was treated with the peptide vaccine and UFT+LV for $\sim 1$ year. The tumor grew slightly after the vaccination, but the patient was deemed to have SD in July 2009 (Fig. 4C). After a CT examination confirmed SD, the tumor remained a consistent size for 421 days and the OS of the patient after enrollment in this trial was 1,024 days. At the end of the investigation (December 2009), 8 patients were diagnosed with PD. The reasons for disease progression were lesion enlargement in 7 patients and discovery of a new lesion in 1 (data not shown). No changes in the ratios of regulatory $\mathrm{T}$ cells and $\mathrm{CD} 8^{+} \mathrm{T}$ cells (naïve, memory, effector memory and effector) were observed in the patients during therapy (data not shown). 
A

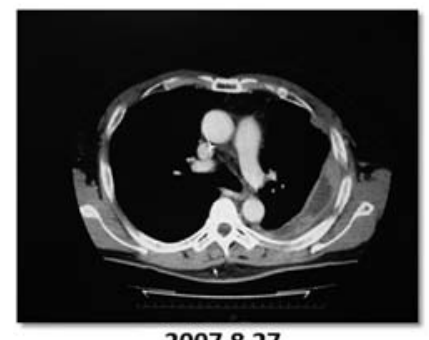

2007.8.27

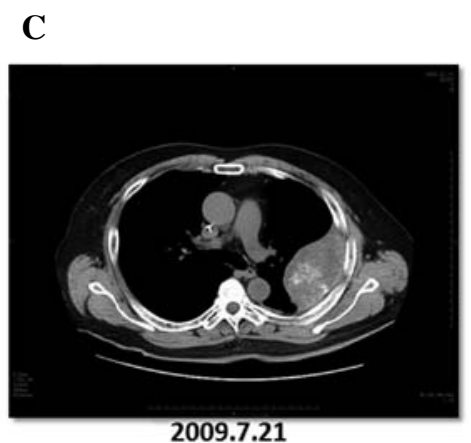

Figure 4. Patient no. 4 (metastasis of rectal cancer to pleura). (A) Metastasis of rectal cancer was apparent in the pleura in August 2007. (B) The patient underwent chemotherapy for approximately 10 months. Based on tumor size, the patient was deemed to have PD in July 2008 after chemotherapy. Since August 2008, the patient received peptide vaccine treatment. (C) The tumor grew slightly, but based on tumor size the patient was deemed to have SD in July 2009.

\section{Discussion}

Vaccine therapy using dendritic cells has been reported to be clinically effective (11), therefore cancer treatment capitalizing on the body's immunocompetence should be possible. However, Nagorsen and Thiel (12) conducted a meta-analysis of tumor-specific immune therapies used to treat colon cancer in 2006. They reported a low clinical response rate $(0.9 \%)$ to these therapies despite a cellular immune response being induced in $44 \%$ of patients after therapy (12). Moreover, Rosenberg et al (13) also reported that vaccine therapy alone did not provide a sufficient clinical response. Given these facts, new breakthroughs in cancer immunotherapies are expected. The search for cancer antigens through exhaustive gene profiling using microarrays, a technique that has recently been put to extensive use, has identified potential new peptide vaccine therapies for cancer. Clinical trials of these therapies are actively underway at a number of facilities. In fact, a report of patients responding well to peptide vaccines has recently emerged (14).

TOMM34 and RNF43 peptides are cancer antigens that are created artificially based on gene profiling data. We previously used real-time PCR to analyze TOMM34 and RNF43 gene expression in samples prepared from paraffin-embedded colon cancer tissues, revealing TOMM34 expression in 78.9\% and RNF43 expression in $63.2 \%$ of cases (data not shown). The cancer antigens that should be used in vaccines are: i) those antigens expressed only by cancer cells and not expressed by normal cells; ii) those antigens that sustain cancer cell func- tion and that lead to cancer cell death when diminished; and iii) those antigens that effectively induce CTLs. TOMM34 and RNF43 may satisfy these criteria. Under normal conditions, cancerous cells are destroyed by immune surveillance when they initially appear. However, cancer cells may lose their antigens and thus escape immune surveillance. One way cancer cells escape surveillance is by losing HLA molecules. Even if CTLs recognizing TOMM34 and RNF43 are induced by a peptide vaccine in vivo, they may ignore cancer cells when the cancer cells lose HLA molecules and escape immune surveillance. Thus, VEGFR1 and VEGFR2 peptides were used in the vaccination to inhibit tumor vascular growth in addition to TOMM34 and RNF43. The vaccine was intended to have antitumor action even in the event that the cancer cells had escaped immune surveillance.

Oral anticancer drugs were used in this trial even though these drugs are thought to inhibit the immune system in vivo. In fact, numerous reports have mentioned achieving enhanced immunity by approaches such as reducing tumor volume through the use of antitumor agents, stimulation of tumor antigens in cancer cells, increasing the CTL response to cancer cells, decreasing regulatory $\mathrm{T}$ cells in vivo, inhibiting production of immune inhibitory cytokines (e.g. TGF- $\beta$ ) and increasing accumulation of immune effector cells in tumor tissue (15-24). In the present trial, therapy was followed by UFT+LV in anticipation of the added immunological response to those agents. UFT+LV is taken orally and does not differ from intravenous 5FU+LV in terms of OS and PFS. Furthermore, no grade 3 or 4 serious adverse effects have been reported as a result of $\operatorname{UFT}+\mathrm{LV}(8,9)$. Since the patients in the present clinical trial had inoperable advanced or recurrent colon cancer and were unable to undergo chemotherapy, the therapy was debilitating and had little marked effect. However, CTL induction after vaccination was noted and PR was achieved in a patient with CTLs induced to recognize a number of peptides. The patients who had a strong CTL reaction to more than 2 peptides had a clinical response (PR as gauged by tumor size and extended SD). Furthermore, patients with favorable results on the CTL assay had a longer OS and PFS, although the difference was not statistically significant. These phenomena indicate the potential for peptide vaccine therapy. Most patients in this trial ultimately had PD, but the reason for PD in most of these patients was enlargement of an existing lesion; only 1 patient was found to have a new lesion. These findings suggest the potential for peptide vaccine therapy together with UFT+LV to inhibit the recurrence of colorectal cancer after curative surgery.

There were differences in CTL induction depending on the patient, and CTLs were more readily and less readily induced by different peptides. The reasons for these differences should be investigated. In this trial, UFT+LV was administered following the same schedule as for UFT+LV alone. Suitable scheduling of UFT+LV with the peptide vaccine and selection of other anticancer drugs besides UFT+LV are topics for future study.

The only major adverse event presumed to be related to the peptide vaccine was pyrexia. Pyrexia could not be avoided as the therapy induces a tumor-specific immune response in vivo. Moreover, pyrexia did not present a problem 
clinically. The other adverse event was a skin reaction at the vaccination site. Several patients had an intense skin reaction, such as ulceration of the vaccination site. One report indicated that an intense skin reaction is a sign of clinical effectiveness (25). A new vaccine adjuvant mixture should be developed to effectively induce an immune reaction without causing skin problems.

In the present trial, an ELISpot assay was used to predict the clinical efficacy of the therapy. Our study noted a longer survival time with a more intense CTL reaction. However, an ELISpot assay has drawbacks such as its expense and its demands on personnel performing the assay. Simple methods of immune monitoring must be developed to predict clinical efficacy. Given the mechanisms of the immune system, immune therapy presumably requires time to produce an effect in patients. In addition, 1 of the current patients (patient no. 4) had an extended SD (time-to-progression 421 days), thus new statistical techniques are needed to analyze the survival time and progression-free interval.

The safety of the peptide vaccine therapy together with UFT+LV was confirmed. At present, the clinical efficacy of the therapy is not satisfactory. However, peptide-specific CTLs were induced in some patients, thus further study is needed. Additional evidence is needed to overcome problems with the therapy and should lead to a standard therapy in the future. Peptide vaccine therapy should not be a standard therapy only for patients with inoperative or advanced cancer, as it was in the present trial, but instead peptide vaccine therapy should be performed as the standard adjuvant therapy for patients with a high risk of postoperative recurrence.

\section{Acknowledgements}

The authors would like to thank Professor Yusuke Nakamura, Dr Takuya Tsunoda, Dr Koji Yoshida, Laboratory of Molecular Medicine, Human Genome Center, Institute of Medical Science, the University of Tokyo, for their excellent advice, cooperation and provision of all the peptides.

\section{References}

1. Shimokawa T, Matsushima S, Tsunoda T, Tahara H, Nakamura $Y$ and Furukawa Y: Identification of TOMM34, which shows elevated expression in the majority of human colon cancers, as a novel drug target. Int J Oncol 29: 381-386, 2006.

2. Lin YM, Furukawa Y, Tsunoda T, Yue CT, Yang KC and Nakamura Y: Molecular diagnosis of colorectal tumors by expression profiles of 50 genes expressed differentially in adenomas and carcinomas. Oncogene 21: 4120-4128, 2002.

3. Yagyu R, Furukawa Y, Lin YM, Shimokawa T, Yamamura T and Nakamura Y: A novel oncoprotein RNF43 functions in an autocrine manner in colorectal cancer. Int J Oncol 25: 1343-1348, 2004.

4. Soker S, Takashima S, Miao HQ, Neufeld G and Klagsbrun M: Neuropilin-1 is expressed by endothelial and tumor cells as an isoform-specific receptor for vascular endothelial growth factor. Cell 92: 735-745, 1998.

5. Niethammer AG, Xiang R, Becker JC, Wodrich H, Pertl U, Karsten G, Eliceiri BP and Reisfeld RA: A DNA vaccine against VEGF receptor 2 prevents effective angiogenesis and inhibits tumor growth. Nat Med 8: 1369-1375, 2002.

6. Li Y, Wang MN, Li H, King KD, Bassi R, Sun H, Santiago A, Hooper AT, Bohlen P and Hicklin DJ: Active immunization against the vascular endothelial growth factor receptor flk1 inhibits tumor angiogenesis and metastasis. J Exp Med 195: 1575-1584, 2002.
7. Wada S, Tsunoda T, Baba T, Primus FJ, Kuwano H, Shibuya M and Tahara $\mathrm{H}$ : Rationale for antiangiogenic cancer therapy with vaccination using epitope peptides derived from human vascular endothelial growth factor receptor 2. Cancer Res 65: 4939-4946, 2005.

8. Douillard JY, Hoff PM, Skillings JR, Eisenberg P, Davidson N, Harper P, Vincent MD, Lembersky BC, Thompson S, Maniero A and Benner SE: Multicenter phase III study of uracil/tegafur and oral leucovorin versus fluorouracil and leucovorin in patients with previously untreated metastatic colorectal cancer. J Clin Oncol 20: 3605-3616, 2002.

9. Carmichael J, Popiela T, Radstone D, Falk S, Borner M, Oza A, Skovsgaard T, Munier S and Martin C: Randomized comparative study of tegafur/uracil and oral leucovorin versus parenteral fluorouracil and leucovorin in patients with previously untreated metastatic colorectal cancer. J Clin Oncol 20: 3617-3627, 2002.

10. Therasse P, Arbuck SG, Eisenhauer EA, Wanders J, Kaplan RS, Rubinstein L, Verweij J, Van Glabbeke M, van Oosterom AT, Christian MC and Gwyther SG: New guidelines to evaluate the response to treatment in solid tumors. European Organization for Research and Treatment of Cancer, National Cancer Institute of the United States, National Cancer Institute of Canada. J Natl Cancer Inst 92: 205-216, 2000.

11. Sadanaga N, Nagashima H, Mashino K, Tahara K, Yamaguchi H, Ohta M, Fujie T, Tanaka F, Inoue H, Takesako K, Akiyoshi T and Mori M: Dendritic cell vaccination with MAGE peptide is a novel therapeutic approach for gastrointestinal carcinomas. Clin Cancer Res 7: 2277-2284, 2001.

12. Nagorsen D and Thiel E: Clinical and immunologic responses to active specific cancer vaccines in human colorectal cancer. Clin Cancer Res 12: 3064-3069, 2006.

13. Rosenberg SA, Yang JC and Restifo NP: Cancer immunotherapy: moving beyond current vaccines. Nat Med 10: 909-915, 2004.

14. Kono K, Mizukami Y, Daigo Y, Takano A, Masuda K, Yoshida K, Tsunoda T, Kawaguchi Y, Nakamura Y and Fujii H: Vaccination with multiple peptides derived from novel cancer-testis antigens can induce specific T-cell responses and clinical responses in advanced esophageal cancer. Cancer Sci 100: 1502-1509, 2009.

15. Correale P, Cusi MG, Tsang KY, Del Vecchio MT, Marsili S, Placa ML, Intrivici C, Aquino A, Micheli L, Nencini C, Ferrari F, Giorgi G, Bonmassar E and Francini G: Chemo-immunotherapy of metastatic colorectal carcinoma with gemcitabine plus FOLFOX 4 followed by subcutaneous granulocyte macrophage colony-stimulating factor and interleukin-2 induces strong immunologic and antitumor activity in metastatic colon cancer patients. J Clin Oncol 23: 8950-8958, 2005.

16. Correale P, Aquino A, Giuliani A, Pellegrini M, Micheli L, Cusi MG, Nencini C, Petrioli R, Prete SP, De Vecchis L, Turriziani M, Giorgi G, Bonmassar E and Francini G: Treatment of colon and breast carcinoma cells with 5-fluorouracil enhances expression of carcinoembryonic antigen and susceptibility to HLA-A $(*) 02.01$ restricted, CEA-peptide-specific cytotoxic $\mathrm{T}$ cells in vitro. Int J Cancer 104: 437-445, 2003.

17. Dauer M, Herten J, Bauer C, Renner F, Schad K, Schnurr M, Endres $\mathrm{S}$ and Eigler A: Chemosensitization of pancreatic carcinoma cells to enhance $\mathrm{T}$ cell-mediated cytotoxicity induced by tumor lysatepulsed dendritic cells. J Immunother 28: 332-342, 2005.

18. Correale P, Cusi MG, Del Vecchio MT, Aquino A, Prete SP, Tsang KY, Micheli L, Nencini C, La Placa M, Montagnani F, Terrosi C, Caraglia M, Formica V, Giorgi G, Bonmassar E and Francini G: Dendritic cell-mediated cross-presentation of antigens derived from colon carcinoma cells exposed to a highly cytotoxic multidrug regimen with gemcitabine, oxaliplatin, 5-fluorouracil, and leucovorin, elicits a powerful human antigen-specific CTL response with antitumor activity in vitro. J Immunol 175: 820-828, 2005.

19. Sato Y, Fujiwara T, Mine T, Shomura H, Homma S, Maeda Y, Tokunaga N, Ikeda Y, Ishihara Y, Yamada A, Tanaka N, Itoh K, Harada $\mathrm{M}$ and Todo S: Immunological evaluation of personalized peptide vaccination in combination with a 5-fluorouracil derivative (TS-1) for advanced gastric or colorectal carcinoma patients. Cancer Sci 98: 1113-1119, 2007.

20. Correale P, Del Vecchio MT, Di Genova G, Savellini GG, La Placa M, Terrosi C, Vestri M, Urso R, Lemonnier F, Aquino A, Bonmassar E, Giorgi G, Francini G and Cusi MG: 5-Fluorouracil-based chemotherapy enhances the antitumor activity of a thymidylate synthase-directed polyepitopic peptide vaccine. J Natl Cancer Inst 97: 1437-1445, 2005. 
21. Weihrauch MR, Ansén S, Jurkiewicz E, Geisen C, Xia Z, Anderson KS, Gracien E, Schmidt M, Wittig B, Diehl V, Wolf J, Bohlen $\mathrm{H}$ and Nadler LM: Phase I/II combined chemoimmunotherapy with carcinoembryonic antigen-derived HLA-A2-restricted CAP-1 peptide and irinotecan, 5-fluorouracil, and leucovorin in patients with primary metastatic colorectal cancer. Clin Cancer Res 11: 5993-6001, 2005.

22. Harrop R, Drury N, Shingler W, Chikoti P, Redchenko I, Carroll MW, Kingsman SM, Naylor S, Melcher A, Nicholls J, Wassan H, Habib N and Anthoney A: Vaccination of colorectal cancer patients with modified vaccinia Ankara encoding the tumor antigen 5T4 (TroVax) given alongside chemotherapy induces potent immune responses. Clin Cancer Res 13: 4487-4494, 2007.

23. Yuan L, Kuramitsu Y, Li Y, Kobayashi M and Hosokawa M: Restoration of interleukin-2 production in tumor-bearing rats through reducing tumor-derived transforming growth factor beta by treatment with bleomycin. Cancer Immunol Immunother 41: 355-362, 1995.
24. Backus HH, Dukers DF, van Groeningen CJ, Vos W, Bloemena E, Wouters D, van Riel JM, Smid K, Giaccone G, Pinedo HM and Peters GJ: 5-Fluorouracil induced Fas upregulation is associated with apoptosis in liver metastases of colorectal cancer patients. Ann Oncol 12: 209-216, 2001.

25. Sato Y, Shomura H, Maeda Y, Mine T, Une Y, Akasaka Y, Kondo M, Takahashi S, Shinohara T, Katagiri K, Sato M, Okada S, Matsui K, Yamada A, Yamana H, Itoh K and Todo S: Immunological evaluation of peptide vaccination for patients with gastric cancer based on pre-existing cellular response to peptide. Cancer Sci 94: 802-808, 2003. 